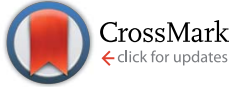

Cite this: RSC Adv., 2016, 6, 94934

Received 18th July 2016

Accepted 27th September 2016

DOI: $10.1039 / c 6 r a 18255 k$

www.rsc.org/advances

\section{Interfacial behaviour of cubic silsesquioxane and silica nanoparticles in Langmuir and Langmuir- Blodgett films}

\begin{abstract}
K. Dopierała, ${ }^{\text {aa }}$ K. Bojakowska, ${ }^{a}$ J. Karasiewicz, ${ }^{b}$ H. Maciejewskib and K. Prochaska ${ }^{\mathrm{a}}$
In recent years fluorinated polyhedral oligomeric silsesquioxanes (POSS) have been established as useful for the fabrication of superhydrophobic surfaces, however little attention has been paid to their use for making ultrathin coatings by the Langmuir-Blodgett method. On the other hand, recently POSS compounds have been recognized as a new group of film-forming materials. In this study the interfacial behavior of fluorinated polyhedral oligomeric silsesquioxanes (POSS) mixed with silica nanoparticles was studied at the air/water interface. Surface pressure-area isotherms and Brewster angle microscopy revealed the formation of a mixed film. Incorporation of nanoparticles in a POSS monolayer caused formation or more condensed and rigid film as shown by analysis of compressibility and dilatational viscoelasticity. On the other hand POSS molecules act as an excellent dispersant which prevents silica nanoparticles from aggregation. Deposition of the Langmuir-Blodgett film composed of POSS and silica nanoparticles allowed a hydrophobic surface showing water contact angles reaching $135^{\circ}$ to be obtained, which suggests possible application of our approach in the fabrication of ultrathin, water-repellent coatings.
\end{abstract}

\section{Introduction}

In recent years materials and their assemblies of dimensions down to a few nanometers have attracted considerable scientific interest. Many techniques have been developed for their synthesis, characterization, functionalization as well as transfer of nanomaterials on solid substrates. ${ }^{1-3}$ Nanoparticles can serve as building blocks for complex thin film structures. In particular, they self-assemble into mono- and multilayers under certain conditions. For instance the Langmuir-Blodgett (LB) technique allows rigid nanomaterials to be aligned in wellordered structures through a flexible assembly process at the air/water interface. This deposition technique is one of the best methods used to manipulate materials at the molecular level. Literature provides a few reports on the fabrication and characterization of the solid particles in Langmuir monolayers and Langmuir-Blodgett films. ${ }^{4}$ Some authors have focused particularly on colloidal silica particles and nanoparticles. ${ }^{5}$ It has been found that hydrophilic silica particles are not stable at the air/ water interface and preferably stay in the water phase. Therefore, in many studies and applications silica particles have been modified by coupling with silane agents ${ }^{6}$ to render the hydrophobic surface.

${ }^{a}$ Institute of Chemical Technology and Engineering, Poznan University of Technology, Berdychowo 4, 60-965 Poznań, Poland. E-mail: katarzyna.dopierala@put.poznan.pl ${ }^{b}$ Faculty of Chemistry, Adam Mickiewicz University, Umultowska 89b, 61-614 Poznań, Poland
Numerous applications of nanoparticles in cosmetics and drugs have fostered a debate on their safety in contact with living cell. For instance, the interest in interactions of nanoparticles with human tissue represented by pulmonary surfactant led to studies on the dynamic behavior of monolayers composed by lipids in the presence of nanosized silica. ${ }^{7,8}$

Currently, research work on silica derivatives is focused on polyhedral oligomeric silsesquioxanes (POSS), which have been recognized as hybrid compounds showing properties inbetween ceramic materials and polymers. Depending on the number and type of functional groups substituted to the rigid silicon-oxygen cage, these compounds may be treated as molecular silica, mono- or multifunctional POSS. ${ }^{9}$ The chemical structure of POSS can be easily modified by substitution of various functional groups, which permits numerous applications. Among all silsesquioxanes fluorinated POSS (F-POSS) deserve special attention due to numerous applications including fabrication of superhydrophobic and superoleophobic materials. ${ }^{10-12}$ The well - defined POSS structure is important for their application in nanocomposites.

It is known that incorporation of nanoparticles into polymeric matrices is an important subject in material engineering. POSS molecules are widely used as stabilizers that ensure appropriate constant distance between single nanoparticles. ${ }^{13}$ The incorporation of POSS into polymer matrices is usually performed via chemical cross-linking or physical blending and thus significant improvement in polymer properties is achieved. ${ }^{14}$ The study of POSS incorporation into polymers has intensified in recent years, revealing new fundamental 
knowledge and unexpected applications. Silsesquioxanes have been often used for surface functionalization of nanoparticles like titanium dioxide for transparent acrylic UV blocking hybrid coating. ${ }^{15}$ Moreover, significant success in novel $\mathrm{SiO}_{2} /$ silane/ POSS functional hybrids has been reported. ${ }^{16}$ Growing interest in promising biomedical applications of silsesquioxanescontaining nanocomposites is also worth mentioning. ${ }^{17,18}$

Several incompletely-condensed POSS materials have been recognized as amphiphilic compounds that organize at the air/ water interface into a monomolecular film. ${ }^{\mathbf{1 9 , 2 0}}$ Therefore using Langmuir technique and the selected POSS molecules one can study the interactions between polymer and these nanofillers in a "two-dimensional" monolayer system. In 2014 we reported the first fully-condensed, multifunctional POSS, octakis[\{2-(3,4epoxycyclohexyl)etyl\}dimethylsilyloxy]octasilsesqui-oxane that forms stable Langmuir film. ${ }^{21}$ Recently, Paczesny et al. demonstrated another fully-condensed, monofunctional POSS compounds bearing glycerol unit, maleamic acid and amino group which behave like typical amphiphiles. ${ }^{22}$ On the other hand, POSS, especially fluorinated derivatives, were recognized as excellent materials for fabrication of water-repellent surfaces. ${ }^{23}$ These findings suggest new, possible approaches to thin film technology with the use of these nanomaterials. To be clear, numerous studies have indicated that POSS compounds are excellent for fabrication of superhydrophobic and oleophobic coatings ${ }^{24-26}$ but little attention has been paid to POSS deposition using Langmuir-Blodgett technique which ensures deposition of well-ordered, ultrathin film of controlled thickness. ${ }^{9,27}$

In this study we investigated partially fluorinated, multifunctional POSS and silica nanoparticles spread together at the air/water interface. While silica nanoparticles are usually used in coating technology for improvement of surface roughness, fluorinated compounds ensure low surface energy. Therefore, the aim of this research was to form the monomolecular film composed of fluorinated POSS molecules and $\mathrm{SiO}_{2}$ nanoparticles at the air/water interface and afterwards to deposit it on a solid substrate. First, we tried to investigate the ability of selected POSS to form uniform monolayer at the air/water interface and study the effect on NP incorporation, then we tested the conditions for successful film deposition using the LB method.

\section{Experimental}

\section{Materials}

The silsesquioxanes used in this study were synthesized according to the method described by Dutkiewicz et al. ${ }^{28}$ Three derivatives with different ratio of fluorinated groups $\left(R_{1}\right)$ to glicydyloxypropyl $\left(\mathrm{R}_{2}\right)$ groups were used: tetrakis $(\{1,1,2,2,3,3,4,4$ octafluor-pentyloxypropyl $\}$ dimethylsiloxy)tetrakis(\{3-glicydoxypropyl $\}$ dimethylsiloxy)octasilsesquioxane, abbreviated as POSS 4:4, (hexakis $(\{1,1,2,2,3,3,4,4$, ,octafluorpentyloxypropyl $\}$ dimethylsiloxy))-bis(\{3-glicydyloxypropyl\}dimethylsiloxy)octasilesquioxane, abbreviated as POSS 6:2 and heptakis $(\{1,1,2,2,3,3,4,4-$ octafluoropentyloxypropyl $\}$ dimethylsiloxy)(\{3-glicydoxypropyl\}dimethylsiloxy)octasilsesquioxane, abbreviated as POSS 7:1, as shown in Fig. 1. Functionalized silica nanoparticles of $15 \mathrm{~nm}$ in diameter dispersed in dimethyformamide $(2.5 \% \mathrm{w} / \mathrm{v})$ were purchased from Sigma Aldrich. For preparation of spreading solutions chloroform of high purity (Uvasol, Merck) was used. The experiments were performed using pure POSS solutions and POSS-nanoparticles (POSS-NP) mixtures at different silica concentrations $(0.5,1.0,1.5$ and $2.0 \%)$ in spreading solution.

\section{Methods}

NMR analysis ${ }^{1} \mathrm{H}$ NMR (300 MHz), ${ }^{13} \mathrm{C}$ NMR (75 MHz), and ${ }^{29} \mathrm{Si}$ NMR $(59 \mathrm{MHz})$ spectra were recorded on a Varian XL 300 spectrometer at room temperature using $\mathrm{C}_{6} \mathrm{D}_{6}$ as a solvent. FTIR spectra were recorded on a Bruker Tensor 27 Fourier trans form spectrom eter equipped with a SPECAC Golden Gate diamond ATR unit.

(Tetrakis $(\{1,1,2,2,3,3,4,4$-octafluoropentyloxypropyl $\}$ dimethylsiloxy))tetrakis(\{3-glicydoxypropyl\}dimethylsiloxy)octasilsesquioxane. ${ }^{1} \mathrm{H}$ NMR $\left(\mathrm{C}_{6} \mathrm{D}_{6}, 298 \mathrm{~K}, 300 \mathrm{MHz}\right) \delta=0.15(\mathrm{~s}$, $\left.48 \mathrm{H}, \mathrm{Si}\left(\mathrm{CH}_{3}\right)_{3}\right) ; 0.60\left(\mathrm{t}, 16 \mathrm{H}, \mathrm{SiCH}_{2}\right) ; 1.63\left(\right.$ qui, $\left.16 \mathrm{H}, \mathrm{CH}_{2}\right) ; 3.53(\mathrm{t}$, $\left.8 \mathrm{H}, \mathrm{CH}_{2} \mathrm{O}\right) ; 3.43\left(\mathrm{~m}, 8 \mathrm{H}, \mathrm{CH}_{2} \mathrm{O}\right) ; 3.89\left(\mathrm{t}, 8 \mathrm{H}, \mathrm{OCH}_{2}\right) ; 3.34(\mathrm{~m}, 4 \mathrm{H}$, $\left.\mathrm{OCH}_{2}\right) ; 3.71\left(\mathrm{~d}, 4 \mathrm{H}, \mathrm{OCH}_{2}\right) ; 6.06\left(\mathrm{t}, 4 \mathrm{H}, \mathrm{CF}_{2} \mathrm{H}\right) ; 3.11(\mathrm{~m}, 4 \mathrm{H}, \mathrm{CH})$; 2.57 (t, $\left.4 \mathrm{H} \mathrm{CH}_{2} \mathrm{Ooxi}\right) ; 2.76\left(\mathrm{t}, 4 \mathrm{H}, \mathrm{CH}_{2} \mathrm{Ooxi}\right)$

${ }^{13} \mathrm{C} \mathrm{NMR}(\mathrm{C} 6 \mathrm{D} 6,298 \mathrm{~K}, 75.5 \mathrm{MHz}) \delta=-0.64\left(\mathrm{Si}\left(\mathrm{CH}_{3}\right)_{2}\right) ; 13.60$ $\left(\mathrm{SiCH}_{2}\right) ; 23.07\left(\mathrm{CH}_{2}\right) ; 43.98\left(\mathrm{CH}_{2} \mathrm{Ooxi}\right) ; 50.68(\mathrm{CH}) ; 67.33\left(\mathrm{OCH}_{2}\right)$; $71.36\left(\mathrm{OCH}_{2}\right) ; 73.96\left(\mathrm{CH}_{2} \mathrm{O}\right) ; 75.47\left(\mathrm{CH}_{2} \mathrm{O}\right) ; 104.27\left(\mathrm{CF}_{2}\right) ; 107.62$ $\left(\mathrm{CF}_{2}\right) ; 110.98\left(\mathrm{CF}_{2} \mathrm{H}\right) ; 115.5\left(\mathrm{CF}_{2}\right)$ ppm.

${ }^{29} \mathrm{Si} \mathrm{NMR}\left(\mathrm{C}_{6} \mathrm{D}_{6}, 298 \mathrm{~K}, 59.6 \mathrm{MHz}\right) \delta=13.07\left(\mathrm{Si}\left(\mathrm{CH}_{3}\right)_{2}\right)$; -109.06 (SiOSi) ppm.

(Hexakis $(\{1,1,2,2,3,3,4,4$-octafluoropentyloxypropyl $\}$ dimethylsiloxy $)$ bis(\{3-glicydoxypropyl $\}$ dimethylsiloxy)octasilsesquioxane. ${ }^{1} \mathrm{H} \mathrm{NMR}\left(\mathrm{C}_{6} \mathrm{D}_{6}, 298 \mathrm{~K}, 300 \mathrm{MHz}\right) \delta=0.14\left(\mathrm{~s}, 48 \mathrm{H}, \mathrm{Si}\left(\mathrm{CH}_{3}\right)\right.$ 3); 0.59 (t, $16 \mathrm{H}, \mathrm{SiCH}_{2}$ ); 1.62 (qui, $16 \mathrm{H}, \mathrm{CH}_{2}$ ); 3.53 (t, $12 \mathrm{H}$, $\left.\mathrm{CH}_{2} \mathrm{O}\right) ; 3.43\left(\mathrm{~m}, 4 \mathrm{H}, \mathrm{CH}_{2} \mathrm{O}\right) ; 3.89\left(\mathrm{t}, 12 \mathrm{H}, \mathrm{OCH}_{2}\right) ; 3.34(\mathrm{~m}, 2 \mathrm{H}$, $\left.\mathrm{OCH}_{2}\right) ; 3.69\left(\mathrm{~d}, 2 \mathrm{H}, \mathrm{OCH}_{2}\right) ; 6.05\left(\mathrm{t}, 6 \mathrm{H} \mathrm{CF}_{2} \mathrm{H}\right) ; 3.11(\mathrm{~m}, 2 \mathrm{H}, \mathrm{CH})$; $2.58\left(\mathrm{t}, 2 \mathrm{H}, \mathrm{CH}_{2} \mathrm{Ooxi}\right) ; 2.77$ (t, 2H, $\left.\mathrm{CH}_{2} \mathrm{Ooxi}\right)$.
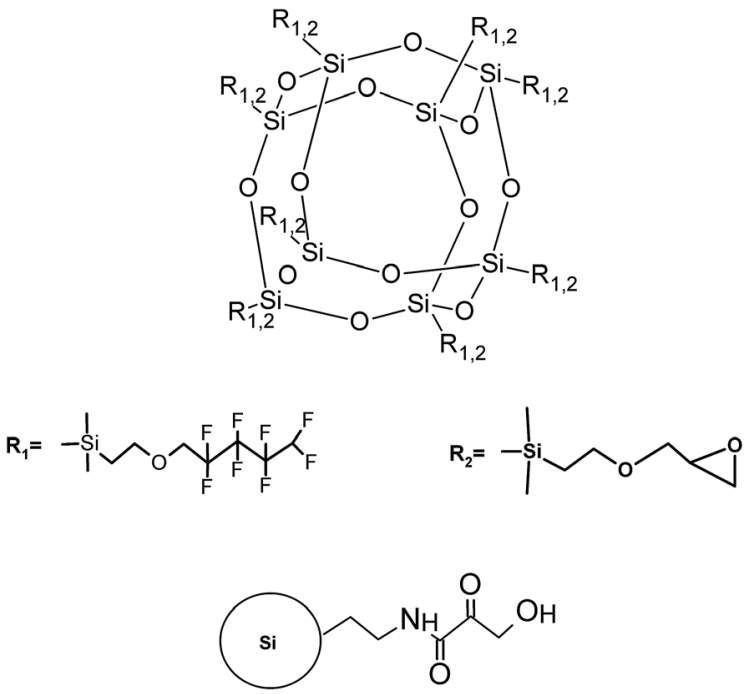

Fig. 1 The chemical structures of the silsesquioxane cage with substituents (on the top) and 3-aminopropyl(3-oxobutanoic acid) functionalized silica (on the bottom). 
${ }^{13} \mathrm{C} \mathrm{NMR}\left(\mathrm{C}_{6} \mathrm{D}_{6}, 298 \mathrm{~K}, 75.5 \mathrm{MHz}\right) \delta=-0.56\left(\mathrm{Si}\left(\mathrm{CH}_{3}\right)_{2}\right) ; 13.34$ $\left(\mathrm{SiCH}_{2}\right) ; 22.99\left(\mathrm{CH}_{2}\right) ; 44.15\left(\mathrm{CH}_{2} \mathrm{Ooxi}\right) ; 50.80(\mathrm{CH}) ; 67.44\left(\mathrm{OCH}_{2}\right)$; $71.47\left(\mathrm{OCH}_{2}\right) ; 74.07\left(\mathrm{CH}_{2} \mathrm{O}\right) ; 75.57\left(\mathrm{CH}_{2} \mathrm{O}\right) ; 105.12\left(\mathrm{CF}_{2}\right) ; 107.64$ $\left(\mathrm{CF}_{2}\right) ; 110.17\left(\mathrm{CF}_{2} \mathrm{H}\right) ; 115.55\left(\mathrm{CF}_{2}\right) \mathrm{ppm}$.

${ }^{29} \mathrm{Si}$ NMR $\left(\mathrm{C}_{6} \mathrm{D}_{6}, 298 \mathrm{~K}, 59.6 \mathrm{MHz}\right) \delta=13.02\left(\mathrm{Si}\left(\mathrm{CH}_{3}\right)_{2}\right)$; -108.97 (SiOSi) ppm.

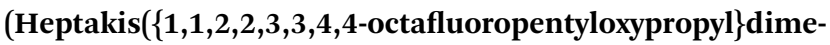
thylsiloxy))(\{3-glicydoxypropyl\}dimethylsiloxy)octasilsesquioxane. ${ }^{1} \mathrm{H} \mathrm{NMR}\left(\mathrm{C}_{6} \mathrm{D}_{6}, 298 \mathrm{~K}, 300 \mathrm{MHz}\right) \delta=0.14\left(\mathrm{~s}, 48 \mathrm{H}, \mathrm{Si}\left(\mathrm{CH}_{3}\right)_{3}\right)$; 0.60 (t, 16H, $\mathrm{SiCH}_{2}$ ); 1.62 (qui, $16 \mathrm{H}, \mathrm{CH}_{2}$ ); $3.53\left(\mathrm{t}, 14 \mathrm{H}, \mathrm{CH}_{2} \mathrm{O}\right.$ ); $3.43\left(\mathrm{~m}, 2 \mathrm{H}, \mathrm{CH}_{2} \mathrm{O}\right) ; 3.89\left(\mathrm{t}, 14 \mathrm{H}, \mathrm{OCH}_{2}\right) ; 3.34\left(\mathrm{~m}, 1 \mathrm{H}, \mathrm{OCH}_{2}\right)$; 3.69 (d, $\left.1 \mathrm{H}, \mathrm{OCH}_{2}\right) ; 6.05\left(\mathrm{t}, 7 \mathrm{H}, \mathrm{CF}_{2} \mathrm{H}\right) ; 3.11(\mathrm{~m}, 1 \mathrm{H}, \mathrm{CH}) ; 2.58(\mathrm{t}$, $1 \mathrm{H}, \mathrm{CH}_{2} \mathrm{Ooxi}$ ); 2.77 (t, $\left.1 \mathrm{H}, \mathrm{CH}_{2} \mathrm{Ooxi}\right)$.

${ }^{13} \mathrm{C}$ NMR $\left(\mathrm{C}_{6} \mathrm{D}_{6}, 298 \mathrm{~K}, 75.5 \mathrm{MHz}\right) \delta=-0.58\left(\mathrm{Si}\left(\mathrm{CH}_{3}\right)_{2}\right) ; 13.37$ $\left(\mathrm{SiCH}_{2}\right) ; 23.02\left(\mathrm{CH}_{2}\right) ; 44.02\left(\mathrm{CH}_{2} \mathrm{Ooxi}\right) ; 50.82(\mathrm{CH}) ; 67.44\left(\mathrm{OCH}_{2}\right)$; $71.5\left(\mathrm{OCH}_{2}\right) ; 74.1\left(\mathrm{CH}_{2} \mathrm{O}\right) ; 75.61\left(\mathrm{CH}_{2} \mathrm{O}\right) ; 104.35\left(\mathrm{CF}_{2}\right) ; 107.72$ $\left(\mathrm{CF}_{2}\right) ; 111.82\left(\mathrm{CF}_{2} \mathrm{H}\right) ; 115.62\left(\mathrm{CF}_{2}\right) \mathrm{ppm}$.

${ }^{29} \mathrm{Si} \mathrm{NMR}\left(\mathrm{C}_{6} \mathrm{D}_{6}, 298 \mathrm{~K}, 59.6 \mathrm{MHz}\right) \delta=13.07\left(\mathrm{Si}\left(\mathrm{CH}_{3}\right)_{2}\right)$; -109.58 (SiOSi) ppm.

Isotherm experiment. All reported isotherm experiments were performed using a Langmuir trough (KSV Nima) of the surface area $273 \mathrm{~cm}^{2}(364 \times 75 \mathrm{~mm})$ filled with ultrapure water $(18 \mathrm{M} \Omega$ $\left.\mathrm{cm}, 71.98 \pm 0.01 \mathrm{mN} \mathrm{m}^{-1}\right)$. Platinum Wilhelmy plate connected with the balance, measured the surface pressure $\pi$ to a resolution of $4 \mu \mathrm{N} \mathrm{m}^{-1}$ as a function of the mean molecular area $(A)$ expressed in $\AA^{2}$. After 20 minutes the $\pi-A$ isotherm was obtained upon symmetrical compression of the liquid surface due to movement of the barriers. This time was checked to be sufficient for chloroform evaporation and equal nanoparticles distribution in POSS-NP mixtures. During all measurements the temperature was kept constant by a Julabo circulator. Before the experiment, the surface of the subphase was cleaned using a suction pump (supplied by KSV Nima) until the change in the surface pressure after maximum compression was below 0.2 $\mathrm{mN} \mathrm{m}{ }^{-1}$. The spreading of all samples on the subphase was made with a gas-tight Hamilton microliter syringe. The compression was performed at a constant rate $\left(5 \mathrm{~mm} \mathrm{~min}^{-1}\right)$. Each experiment was repeated at least three times to ensure the reproducibility of the curves to $\pm 2 \AA^{2}$. Floating optical table (Standa) under the Langmuir trough and all other devices reduced vibrations and Laminar flow hood (Alpina) surrounding the equipment eliminated dust from the environment.

Brewster angle microscopy. Brewster angle microscope MiniBAM (KSV Nima) connected with Langmuir trough was used to visualize the morphology of the films. Domains of different shapes and sizes observed as different reflection density or different grey levels indicate the monolayer phases. This morphology reflects also changes in the monolayer thickness due to formation of three-dimensional aggregates. The laser diode $(659 \mathrm{~nm})$ was used as light source. The camera had the field of view $3.6 \times 4.0 \mathrm{~mm}$ and the resolution was approx. 6 microns per pixel (i.e. better than 12 micron resolution according to Rayleigh's criterion; the system is not diffraction limited). A flat black glass plate was placed under the subphase to absorb the refracted beam. BAM images were taken simultaneously with film compression at different surface pressures.
Dilational rheology. Dilational viscoelasticity of the films was investigated with the use of the oscillating barrier method. This technique is particularly suitable for evaluation of stability of the monolayers in dynamic conditions. Upon stress application, the monolayer undergoes area deformation. The monolayer was first compressed to a desired surface pressure and left for relaxation. The surface pressures chosen for measurements $(4$, 8, 12, 16 and $20 \mathrm{mN} \mathrm{m}^{-1}$ ) corresponded to expanded, condensed and collapsed states of the films. After 20 minutes the available area started to change due to small amplitude oscillations of the barriers. The amplitude was 1\%. During the oscillations, the surface pressure response was continuously recorded. Ten frequencies ranging from 0.02 to $0.15 \mathrm{~Hz}$ were chosen for every single surface pressure value.

The relationship between stress and area deformation provides information on the viscoelastic properties of the monolayer. The dilatational modulus $\mathrm{E}$ is a complex quantity composed of the real component-elastic modulus, $E^{\prime}$ and imaginary component, viscous modulus, $E^{\prime \prime}$, and it is defined by the equation: ${ }^{29}$

$$
E=E^{\prime}+\mathrm{i} E^{\prime \prime}
$$

The imaginary part is equal zero when a monolayer is perfectly elastic, while for a perfectly viscous material, the real part is zero. The loss angle tangent, $\tan \theta$ can be defined as the ratio of $E^{\prime \prime}$ to $E^{\prime}$. If $\tan \theta>1$, the monolayer has more viscous character, while $\tan \theta<1$ implies elastic behavior. For most systems encountered in industry and in biological systems these relationships are nonlinear and the observed behavior is intermediate between purely viscous and purely elastic.

Deposition and characterization of Langmuir-Blodgett films. For preparation of an LB film, the POSS-NP mixture was spread at the air/water interface and compressed to a desired surface pressure. After $\sim 20$ minutes the film was transferred onto a glass plate followed by careful cleaning of the substrate by RCA1 solution. The deposition was performed during one upward stroke of a dipper operated together with LangmuirBlodgett trough by KSV Nima software. The quality of the film can be described by the transfer ratio (TR), which is defined as the ratio between the decrease in monolayer area during a deposition stroke and the area of the substrate. For ideal transfer, TR is equal to 1 . After drying the plate, advancing contact angle (WCA) was measured using the drop shape method (Tracker, IT Concept) using ultrapure water as the liquid. The average WCA for clean glass was $5.3^{\circ} \pm 0.9$. Each measurement was repeated three times and the average values were reported.

\section{Results and discussion}

\section{Isotherm studies}

In the first stage of this study we obtained $\pi-A$ isotherms for pure silsesquioxanes. Fig. 2 reports the $\pi-A$ isotherms of three compounds: POSS 4:4, POSS 7:1 and POSS 6:2. All the isotherms show monotonous expanded-like shape without typical phase transitions. The initial area per molecule of the monolayers at 


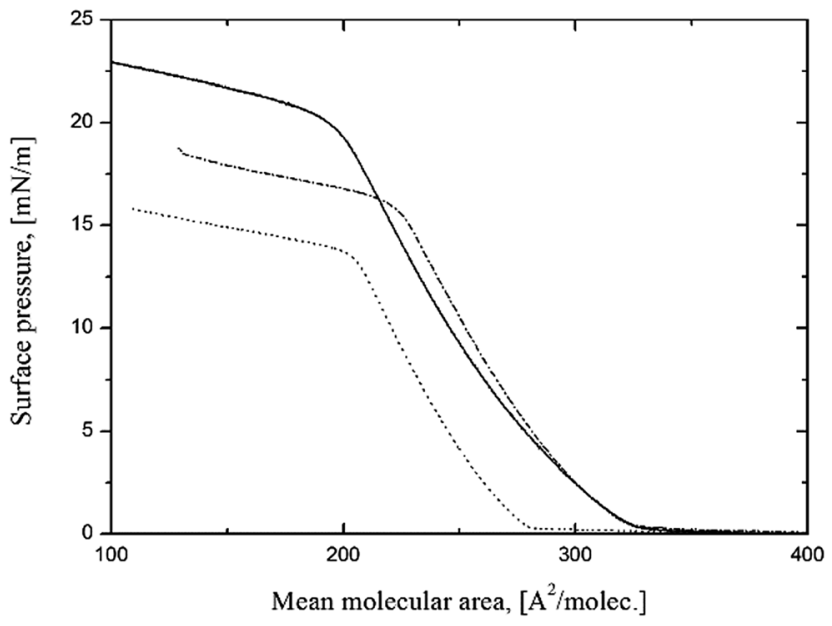

Fig. 2 The $\pi-A$ isotherms of (-) POSS 4:4, (---) POSS 6:2, (.....) POSS $7: 1$ at $25^{\circ} \mathrm{C}$.

the initial increase in surface pressure $\left(A_{\text {lift-off }}\right)$ was found to be higher than typical values for incompletely condensed silsesquioxanes ( 135-200 $\AA^{2}$ per molec.), which are stable at the interface. The value of $A_{\text {lift-off }}$ shown for POSS 7:1 was rather closer to the reported value for film-forming, fully-condensed octakis[\{2-(3,4-epoxycyclohexyl)etyl $\}$ dimethylsilyloxy]octasilsesquioxane (OE-POSS) that occupies $260 \AA^{2}$ per molec. at the air/water interface because of bulky substituents attached to the siliconoxygen cage. ${ }^{18}$ Limiting areas $\left(A_{\text {lim }}\right)$ determined by the extrapolation of the slope of the isotherm at condensed state to $\pi=$ $0 \mathrm{mN} \mathrm{m}^{-1}$, for POSS 7:1 are also similar to those obtained for the mentioned OE-POSS. Taking into account a similar chemical structure of both compounds, one can assume, that POSS 7:1 forms a monomolecular film at the air/water interface. This issue will be discussed later together with the interpretation of BAM images.

For POSS 6:2 and POSS 4:4 we observed identical values of $A_{\text {lift-off }}$ and only slight differences between limiting areas. The collapse behavior, without characteristic surface pressure decrease, seems to be similar to that of the fully- condensed POSS with glycerol units. ${ }^{22}$

The collapse surface pressure was determined as the interception of two linear regions of the curve. A closer look at the data indicates that the number of fluorinated groups in POSS structure has a significant impact on the collapse surface pressures, $\pi_{\text {coll }}$ which are equal to $14 \mathrm{mN} \mathrm{m}^{-1}, 16 \mathrm{mN} \mathrm{m}^{-1}$ and $20.5 \mathrm{mN} \mathrm{m}^{-1}$ for POSS 7:1, POSS 6:2 and POSS 4:4, respectively. The highest $\pi_{\text {coll }}$ was achieved for the symmetrical POSS $4: 4$ and the lowest for the most hydrophobic POSS 7:1. These finding suggest that 7 fluorinated substituents oriented towards air prevent the monolayer to be compressed to the higher values of $\pi$ and the film is disrupted. It seems that the balance between hydrophobic and hydrophilic substituents is the most favorable for POSS 4:4. Thus, increasing number of fluorinated substituents in POSS cage destabilize the film. For POSS 6:2 and POSS 4:4 there are few possible arrangements of the side groups attached to the silsesquioxanes cage in these compounds, while
POSS 7:1 has very well defined chemical structure. Therefore we decided to focus on POSS 7:1 in further experiments, despite lower collapse surface pressure.

In order to form POSS-NP film at the air/water interface we spread on water subphase a mixture of POSS 7:1 and silica at different NP concentrations. The obtained isotherms, shown in Fig. 3, indicated a significant influence of silica NP on the film properties. The $A_{\text {lift-off }}$ values are higher for POSS-NP mixtures. The area occupied by a single POSS molecule is also greater which suggests incorporation of $\mathrm{SiO}_{2}$ into the film. Moreover, $\pi-A$ isotherms show different shape and indicate a different collapse behavior. Looking for likely explanations of these findings, several possible effects must be taken into account: (I) existence of chemical bonds between functional amine group on the silica surface and terminal glycidyl moiety in POSS molecule; ${ }^{30}$ (II) competition for the available space in water subphase between carboxyl and epoxy groups on the silica surface and in POSS molecules respectively; (III) difference in cross-section areas between functionalized $\mathrm{SiO}_{2}$ and POSS molecules.

According to the typical reaction between amine and epoxy groups during formation epoxy resins, ${ }^{31}$ the $-\mathrm{NH}$ group in functionalized silica NP may react with $\mathrm{H}_{2} \mathrm{C}-\mathrm{O}-\mathrm{CH}_{2}$ group in POSS 7:1. As a result, cross-linked structures can be formed analogous to epoxy resins containing silica nanofiller. ${ }^{32}$ On the other hand the competition between carboxylic group at the silica surface and glycidyl group in POSS molecules may cause both ordering at the interface and molecular reorientations resulting from rejection of glycidyl moieties and replacing them by more hydrophilic carboxylic groups in the initial stages of film formation. Moreover, this competition is strongly dependent on silica concentration. Since silica particle occupies larger area at the interface than a single POSS molecule, this mechanism may play a significant role in the collapse behavior. As shown in Fig. 3 the silica-containing films collapse at higher surface pressures than pure POSS 7:1, however due to a limited

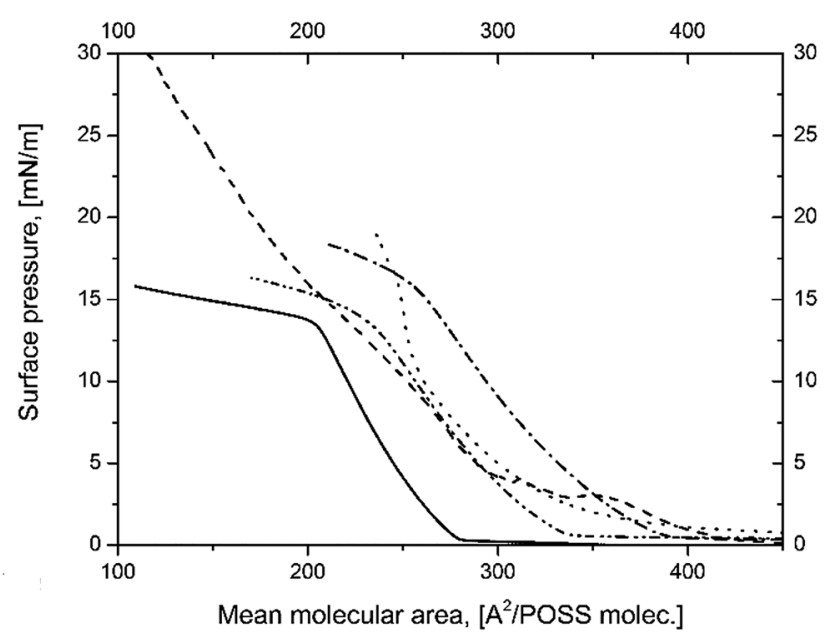

Fig. 3 The $\pi-A$ isotherms of (-) POSS 7:1 (- .. - - POSS 7:1 + $\mathrm{SiO}_{2}$ $0.5 \%,(-\cdots)$ POSS 7:1 $+\mathrm{SiO}_{2} 1 \%,(--)$ POSS 7:1 + $\mathrm{SiO}_{2} 2 \%,(\ldots$.$) POSS$ $7: 1+\mathrm{SiO}_{2} 1.5 \%$ at $25^{\circ} \mathrm{C}$. 
area of the trough it was impossible to determine the exact value of $\pi_{\text {coll }}$ for the mixtures.

Significant difference in silica NP's diameter $(15 \mathrm{~nm})$ and POSS cage may also have impact on the surface pressure-area isotherm.

A typical POSS cage being $0.5 \mathrm{~nm}$ in diameter (without side groups) occupies around much smaller area than a single silica nanoparticle which is $15 \mathrm{~nm}$ in diameter (assuming very high monodispersity of silica, as declared by the supplier). This difference may restrict the interactions between POSS molecules and improve the monolayer stability. On the other hand, POSS moieties distributed between silica nanoparticles may hinder the unfavorable NPs agglomeration.

Moreover, different size of nanomaterials is often necessary in successful fabrication of hydrophobic coatings. For instance Tsai et al. demonstrated the formation of a stable, superhydrophobic surface by coupling of successive LangmuirBlodgett depositions of micro- and nano-sized silica particles on a glass substrate with the formation of a self-assembled monolayer of dodecyltrichlorosilane. ${ }^{33}$

On the basis of $\pi-A$ isotherms, the static elasticity (compressional modulus) was calculated according to the equation: ${ }^{34}$

$$
\mathrm{C}_{\mathrm{s}}^{-1}=-A\left(\frac{\partial \pi}{\partial A}\right)_{t}
$$

Compressional modulus reflects variations in the physical state of monolayers and helps to understand molecular arrangement. According to the criterion given by Davies and Rideal $^{34}$ for liquid-expanded (LE) films, $\mathrm{C}_{\mathrm{s}}{ }^{-1}$ ranges from 12.5 to $50 \mathrm{mN} \mathrm{m}^{-1}$, for liquid-condensed (LC) ones it varies from 50 to 250 and for $\mathrm{C}_{\mathrm{s}}^{-1}>250 \mathrm{mN} \mathrm{m}^{-1}$ solid state (S) is observed. Here, $\mathrm{C}_{\mathrm{s}}{ }^{-1}$ was calculated and plotted as a function of surface pressure for pure POSS and POSS-NP mixtures. Compressional modulus shown in Fig. 4 indicated liquid-expanded film of pure POSS $7: 1$. For mixed system containing 0.5 and $1 \%$ of silica the compressibility of the films are similar to that of POSS $7: 1$.

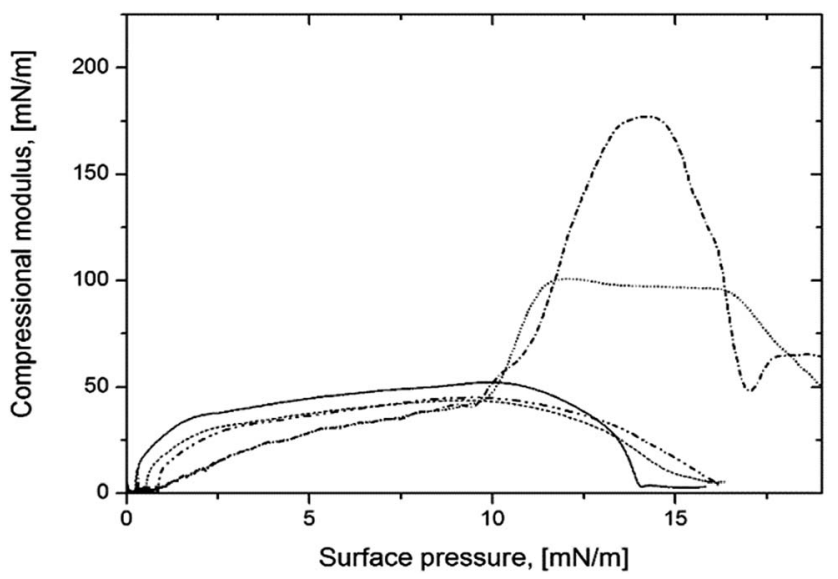

Fig. 4 Compression modulus vs. surface pressure for (-) POSS 7:1, (--) POSS 7:1 $+\mathrm{SiO}_{2}$ 0.5\%, (- -. - - POSS 7:1 $+\mathrm{SiO}_{2} 1 \%,(\cdots$.$) POSS 7:1 +$ $\mathrm{SiO}_{2} 1.5 \%,(-\cdot-)$ POSS 7:1 $+\mathrm{SiO}_{2} 2 \%$.
Addition at least $1.5 \%$ of silica to POSS 7:1 made the film more condensed with $\mathrm{C}_{\mathrm{s}}^{-1}$ values reaching almost 100 . For $2 \%$ silica content, the monolayer is in-between condensed and solid state. Thus, the incorporation of silica NP into POSS film made it more rigid.

\section{BAM images}

Comparison of BAM images taken for pure POSS 7:1 (Table 1A) and those previously described of other POSS leads to the conclusions about the influence of side groups in POSS molecule on the collapse behavior. For OE-POSS we observed a stepwise collapse accompanied with the appearance of bright, flake-like domains attributed to multilayer formation. As a result of further compression, these domains cracked and formed star-like structures. This behavior can be attributed to the presence of eight bulky, epoxycyclohexyl rings in the OEPOSS molecule. For POSS 7:1 we obtained uniform BAM images up to $15 \mathrm{mN} \mathrm{m}^{-1}$ corresponding to formation of homogenous, liquid-like film and randomly shaped three dimensional structures when POSS 7:1 collapsed.

The film morphology observed for co-spread POSS-NP mixtures presented in images in Table 1(B-D) seemed to be strongly depended on the silica content at the interface. For the mixed system with $0.5 \%$ silica concentration, network-like structures are visible in the liquid-expanded monolayer. During the compression, the film became more compact but characteristic network-like morphology is visible up to $17 \mathrm{mN}$ $\mathrm{m}^{-1}$. At this state of compression almost whole surface is covered with homogenous film. Similar morphology was recorded by Paczesny et al. for hydrophobic gold nanoparticles distributed in liquid crystal matrix. ${ }^{35}$ For POSS 7:1+ $\mathrm{SiO}_{2} 1 \%$ we observed also dense network-like structure however at $\pi=17 \mathrm{mN} \mathrm{m}^{-1}$ these domains merge into homogenous layer. For $2 \%$ concentration of silica, we observed stepwise formation of the homogenous film of uniform contrast.

For all silica concentrations BAM images taken during expansion revealed complete respreading of the material and this is why eventual chemical reaction at the interface between functional amine group on the silica surface and terminal glycidyl moiety in POSS molecule must be excluded.

On the other hand it is obvious that silica nanoparticles exhibit a very high specific surface area, which leads to interfacial interactions between the particles and the polymer matrix that mainly govern the new properties of the composites. This high specific surface, however, causes the attraction between NPs due to electrostatic van der Waals' forces and formation of large agglomerates with dimensions of several micrometers. In this case it seems that POSS molecules hinder silica NP aggregation and make the film more ordered.

To sum up the BAM observations, we suggest that distribution of smaller POSS molecules between NP prevents silica from agglomeration at the interface. Thus, silsesquioxane molecules act as excellent dispersants which are required in many applications of nanomaterials. Similar effects have been observed for carbon nanotubes functionalized with POSS. ${ }^{36}$ 
Table 1 BAM images of (A) pure POSS 7:1 monolayer, (B) POSS 7:1 + 0.5\% $\mathrm{SiO}_{2}$, (C) POSS 7:1 + 1.0\% $\mathrm{SiO}_{2}$, (D) POSS 7:1 + 1.5\% $\mathrm{SiO} 2$
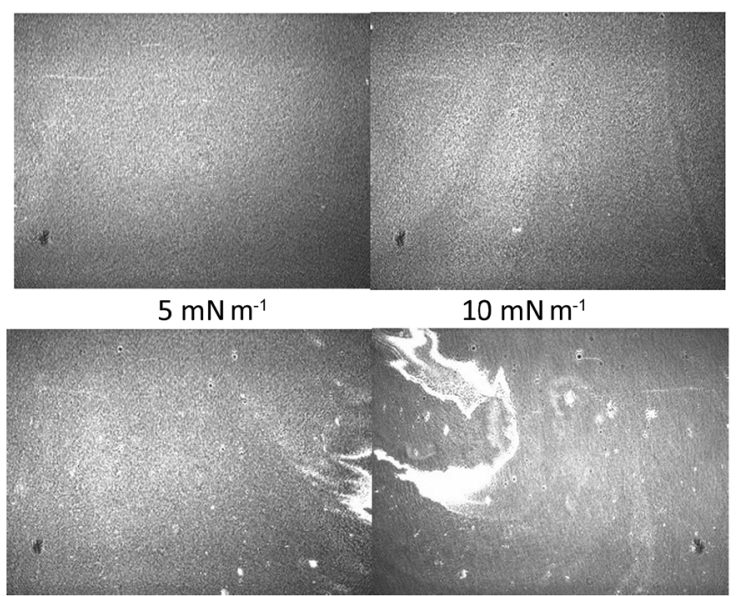

$15 \mathrm{mN} \mathrm{m}^{-1}$

A

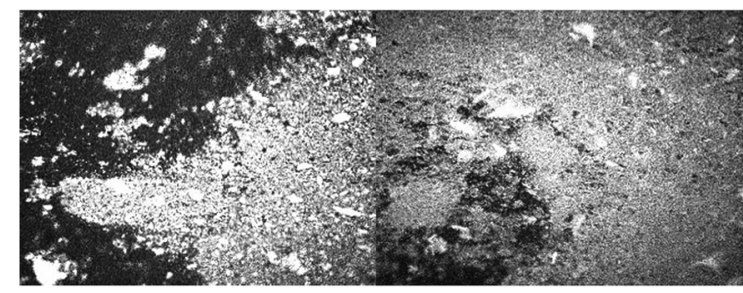

$7 \mathrm{mN} \mathrm{m}^{-1}$

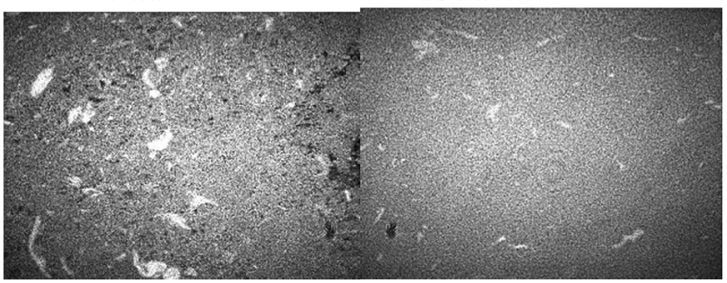

$14 \mathrm{mN} \mathrm{m}^{-1}$

$17 \mathrm{mN} \mathrm{m}^{-1}$

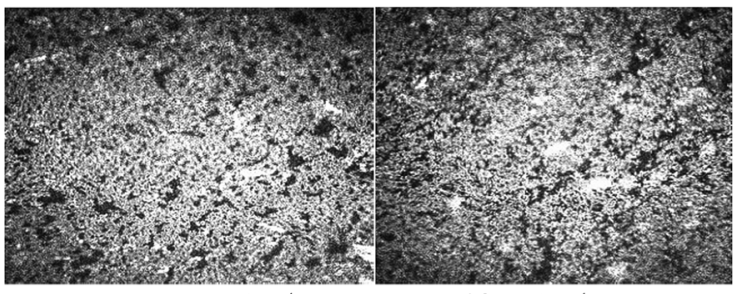

$5 \mathrm{mN} \mathrm{m}^{-1}$

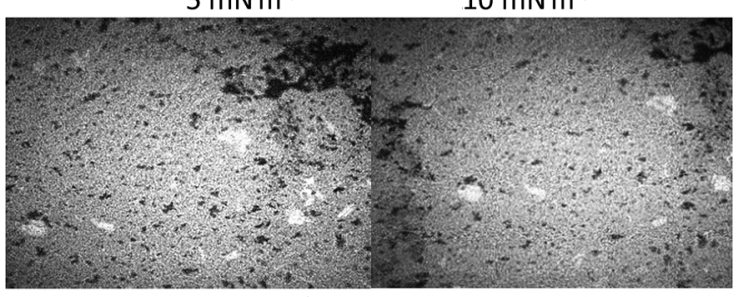

$14 \mathrm{mN} \mathrm{m}^{-1}$

$17 \mathrm{mN} \mathrm{m}^{-1}$

B

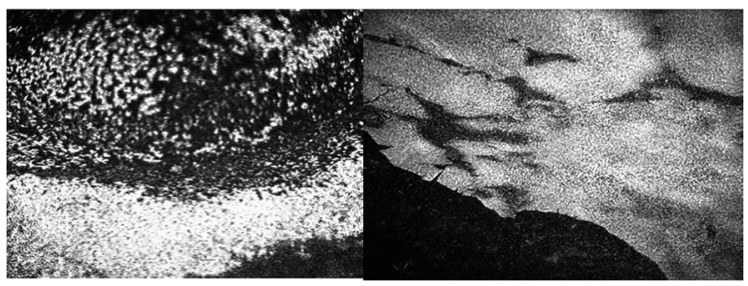

$4 \mathrm{mN} \mathrm{m}^{-1}$

$9 \mathrm{mN} \mathrm{m}^{-1}$

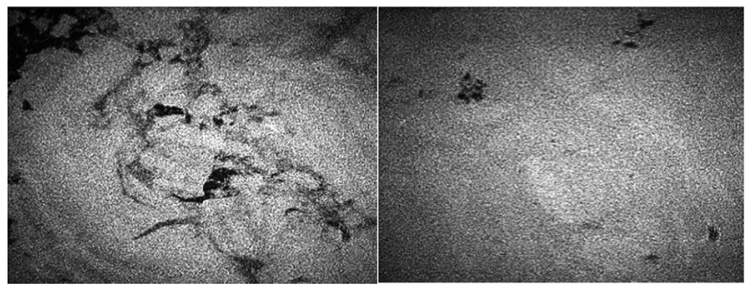

$12 \mathrm{mN} \mathrm{m}^{-1}$

$20 \mathrm{mN} \mathrm{m}^{-1}$

C

D

\section{Dilatational rheology}

In order to investigate the rheological properties of the considered films, we made oscillation barriers experiment for pure POSS 7:1 and a selected mixture, i.e. POSS 7:1 + 1.5\% $\mathrm{SiO}_{2}$. The obtained elastic $\left(E^{\prime}\right)$ and viscous $\left(E^{\prime \prime}\right)$ modulus for different surface pressures are reported in Fig. $5 \mathrm{a}-\mathrm{d}$. The results obtained for pure POSS 7:1 (Fig. 5a and b) indicated that $E^{\prime}$ and $E^{\prime \prime}$ values were strongly affected by monolayer state and frequency. Most results show linear dependence on frequency. For liquidexpanded region $\mathrm{mN} \mathrm{m}^{-1}$, the elastic modulus decreased with the rise of frequency. For $\pi>16 \mathrm{mN} \mathrm{m}^{-1}$, the elastic modulus showed low, frequency-independent values. This effect can be attributed to the stability of the condensed film. For POSS 7:1+ $\mathrm{SiO}_{2}$ 1.5\% we observed also a linear response of both modulus to frequency variations, however the values of $E^{\prime}$ and $E^{\prime \prime}$ were higher than those for pure POSS 7:1. This finding is in agreement with quasi-equilibrium elasticity shown in Fig. 4 and may be related to the fact that the incorporated silica enhanced structural ordering of the monolayer. Similar results have been published by Ravera et al. who demonstrated that mixing of palmitic acid with nanoparticles of highly hydrophobic surface led to formation of solid-like films with high values of elasticity modulus. ${ }^{37}$ Moreover, in the cited study, dilatational response was dependent on the hydrophobization degree of the nanoparticles. In another paper changes in dynamic behavior of DPPC mixtures with NP have been attributed to the formation of hydrophobic nanoparticle-lipid complex. ${ }^{38}$ However, the presence of NP decreased the rigidity of lipid monolayer.

\section{Langmuir-Blodgett films}

On the basis of the compressional modulus curves, we chose two systems: POSS 7:1 $+\mathrm{SiO}_{2} 1.5 \%$ and POSS 7:1 $+\mathrm{SiO}_{2} 2 \%$ to transfer the films onto the solid substrate using the LangmuirBlodgett method. Transfer ratios and advancing contact angles measured on the surface of coated glass are reported in Table 2. From these data we concluded that the quality of the transfer 


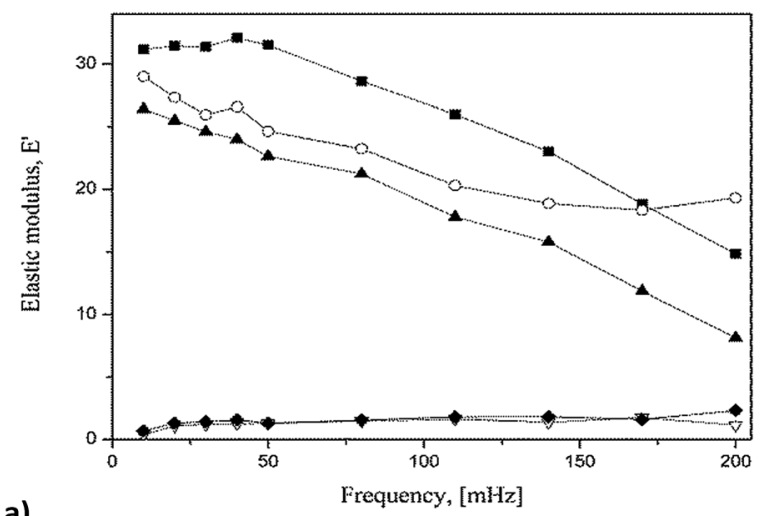

a)

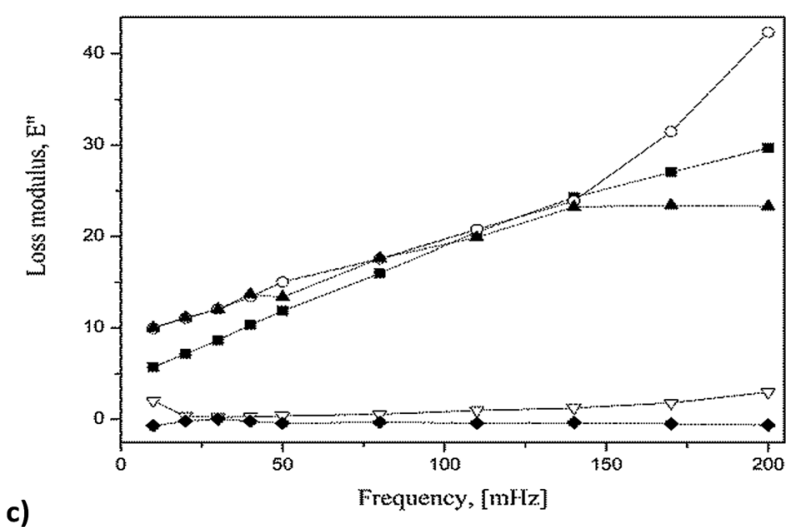

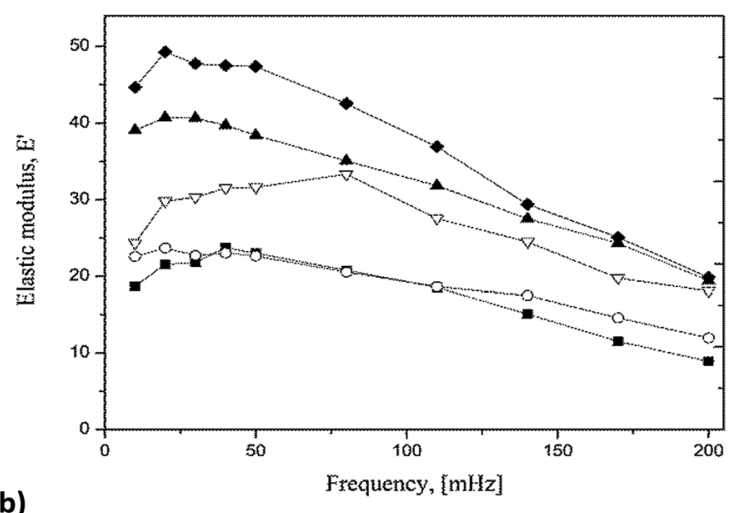

b)

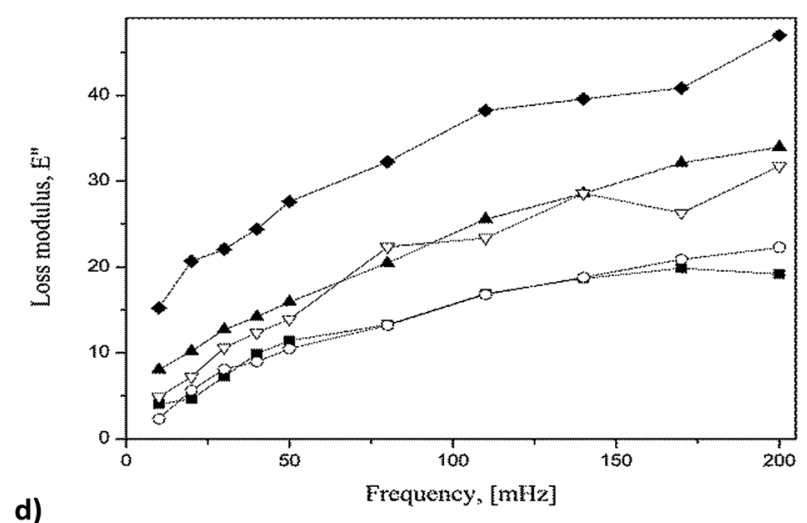

Fig. 5 Elastic modulus $\left(E^{\prime}\right)$ vs. frequency of oscillations for (a) POSS 7:1 and (b) POSS 7:1 $+1.5 \% \mathrm{SiO}_{2}$ as well as loss modulus ( $\left.E^{\prime \prime}\right)$ vs. frequency of oscillations for (c) POSS 7:1 and (d) POSS 7:1 $+\mathrm{SiO}_{2} 1.5 \%$. The symbols mean surfaces pressures: (ם) $4 \mathrm{mN} \mathrm{m}^{-1},(\mathrm{O}) 8 \mathrm{mN} \mathrm{m}^{-1},(\mathbf{\Delta}) 12 \mathrm{mN} \mathrm{m}^{-1}$, $(\nabla) 16 \mathrm{mN} \mathrm{m}^{-1},(\diamond) 20 \mathrm{mN} \mathrm{m}^{-1}$.

Table 2 Transfer ratios (TR) and average water advancing contact angle values (WCA) on glass coated by a single layer of Langmuir-Blodgett film composed of POSS 7:1 $+\mathrm{SiO}_{2} 1.5 \%$ and POSS 7:1 $+\mathrm{SiO}_{2} 2 \%$

\begin{tabular}{|c|c|c|c|c|c|c|c|c|}
\hline Silica concentration, $[\%]$ & 1.5 & 2.0 & 1.5 & 2.0 & 1.5 & 2.0 & 1.5 & 2.0 \\
\hline$\pi,\left[\mathrm{mN} \mathrm{m}^{-1}\right]$ & 5.0 & & 10 & & 15 & & 30 & \\
\hline TR & 1.10 & 0.65 & 1.08 & 0.42 & 1.22 & 0.89 & - & 0.98 \\
\hline WCA, $\left[{ }^{\circ}\right]$ & 90.1 & 130.5 & 98.7 & 135.0 & 115.8 & 134.1 & - & 132.4 \\
\hline
\end{tabular}

depended strongly on the surface pressure and silica concentration. For mixtures with $1.5 \%$ of silica the transfers are a little higher than 1 and for $2 \%$-a little lower than 1 . This suggests that for both mixtures the substrate was coated with a single monolayer of the material. On the other hand, water contact angles were significantly higher for $2 \%$ content of silica and reached around $135.0^{\circ}$ for all monolayer states, while for lower content of NP $(1.5 \%)$ we obtained the highest WCA equal to $115.8^{\circ}$. We believe that this effect can be attributed to fluorinated side groups in POSS molecules which provide low surface energy at the coated surface and increased its roughness caused by nanoparticles. Unfortunately, the receding contact angles (not reported here) obtained during the measurement were very low indicating large hysteresis. It is also possible that crosslinking between POSS and functionalized silica nanoparticles which occurred after mixing weakened the adhesion of silica to the glass.

To improve the quality of the films it is necessary to continue this study by deposition of multilayers using POSS and NP. Nevertheless, our approach caused a significant increase in substrate hydrophobicity with only single monolayer of the material. Taking into account relatively high costs of fluorinated POSS, it seems that the obtained results are show advantage over other coating techniques.

\section{Conclusions}

The results obtained in this work demonstrate that $\mathrm{POSS}-\mathrm{SiO}_{2}$ NP at the air/water interface can serve as model system to study nanofiller effects in polymer systems. Increasing number of 
fluorinated substituents in POSS molecule cause destabilization of the film at the interface, however POSS 7:1 was found to be suitable to form mixed film with silica nanoparticles. Antiaggregation behavior of POSS 7:1 at the interface seemed to be the dominant effect resulting in mixed film formation and its stabilization. Several other phenomena were found to occur at the interface like competition between functional groups for the area occupied at the interface and molecular reorganization leading to equal distribution of nanoparticles. Large differences in cross-sectional areas of POSS and $\mathrm{SiO}_{2}$ molecules implied variations in the course of $\pi-A$ isotherms and film morphology. Our results confirmed incorporation of silica nanoparticles into POSS monolayer. Moreover, addition of silica to POSS monolayer made the film more condensed and rigid. We succeed in deposition of the mixed film on the solid substrate obtaining hydrophobic ultrathin Langmuir-Blodgett film. Taking into account the results of our previous study, ${ }^{23}$ this paper can be assumed as a new stage in fabrication of highly hydrophobic coatings composed of POSS and nanoparticles.

\section{Acknowledgements}

This work was financially supported by National Science Centre in Poland, Grant No. UMO-2012/05/B/ST02200.

\section{References}

1 K. Dopierala, H. Maciejewski, J. Karasiewicz and K. Prochaska, Appl. Surf. Sci., 2013, 283, 453.

2 D. Meroni, S. Ardizzone, G. Cappelletti, M. Ceotto, M. Ratti, R. Annunziata, M. Benaglia and I. Raimondi, J. Phys. Chem. C, 2011, 115, 18649.

3 G. Soliveri, R. Annunziata, S. Ardizzone, G. Cappelletti and D. Meroni, J. Phys. Chem. C, 2012, 116, 26405.

4 J. Y. Park and R. C. Advincula, Soft Matter, 2011, 7, 9829.

5 A. Deák, I. Székely, E. Kálmán, Z. Keresztes, A. L. Kovácsc and

Z. Hòrövflgyi, Thin Solid Films, 2005, 484, 310.

6 T. Jesionowski, Compos. Interfaces, 2009, 16, 115.

7 E. Guzman, L. Liggieri, E. Santini, M. Ferrari and F. Ravera, J. Phys. Chem. C, 2011, 115, 21715.

8 E. Guzmán, L. Liggieri, E. Santini, M. Ferrari and F. Ravera, Colloids Surf., A, 2012, 413, 174.

9 D. B. Cordes, P. D. Lickiss and F. Rataboul, Chem. Rev., 2010, 110, 2081.

10 H. Maciejewski, J. Karasiewicz, M. Dutkiewicz and B. Marciniec, Silicon, 2015, 7, 201.

11 H. Wang, Y. Xue, J. Ding, L. Feng, X. Wang and T. Lin, Angew. Chem., Int. Ed., 2011, 50, 11433.

12 A. Tuteja, W. Choi, M. Ma and J. M. Mabry, Science, 2007, 318, 1618.

13 S.-W. Kuo, Y.-C. Wu, C.-H. Lu and F.-C. Chang, J. Polym. Sci., Part B: Polym. Phys., 2009, 47, 811.
14 E. B. Sarkar and P. Alexandridis, Nanomaterials, 2012, 2, 445. 15 J. Godnjaveca, B. Znoja, N. Veronovski and P. Venturini, Prog. Org. Coat., 2012, 74, 654.

16 K. Szwarc-Rzepka, T. Szatkowski, F. Ciesielczyk and T. Jesionowski, Abbreviated Title, 2013, 49, 673.

17 H. Ghanbari, B. G. Cousins and A. M. Seifalian, Macromol. Rapid Commun., 2011, 32, 1032.

18 Applications of Polyhedral Oligomeric Silsesquioxanes, ed. C. Hartmann-Thompson, Springer, 2011.

19 J. Deng, J. T. Polidan, J. R. Hottle, C. E. Farmer-Creely, B. D. Viers and A. R. Esker, J. Am. Chem. Soc., 2002, 124, 15194.

20 J. Deng, D. Brent, B. D. Viers and A. R. Esker, Langmuir, 2005, 21, 2375.

21 K. Dopierala, A. Wamke, M. Dutkiewicz, H. Maciejewski and K. Prochaska, J. Phys. Chem. C, 2014, 118, 24548.

22 J. Paczesny, I. Binkiewicz, M. Janczuk, K. Wybrańska, Ł. Richter and R. Hołyst, J. Phys. Chem. C, 2015, 119, 27007.

23 H. Maciejewski, J. Karasiewicz, M. Dutkiewicz, M. Nowicki and Ł. Majchrzycki, RSC Adv., 2014, 4, 52668.

24 V. Anand Ganesh, A. Sreekumaran Nair, H. K. Raut, T. T. Y. Tan, C. He, S. Ramakrishnaae and J. Xu, J. Mater. Chem., 2012, 22, 18479.

25 X. Lia, K. Zhanga, Y. Zhaoa, K. Zhub and X. Yuan, Prog. Org. Coat., 2015, 89, 150.

26 J. A. Kleingartner, S. Srinivasan, Q. T. Truong, M. Sieber, R. E. Cohen and G. H. McKinley, Langmuir, 2015, 31, 13201.

27 A. Wamke, K. Dopierała, K. Prochaska, H. Maciejewski, A. Biadasz and A. Dudkowiak, Colloids Surf., A, 2015, 464, 110.

28 M. Dutkiewicz, H. Maciejewski, B. Marciniec and J. Karasiewicz, Organometallics, 2011, 30, 2149.

29 A. L. Caro, M. R. Nino and J. M. R. Patino, Colloids Surf., A, 2008, 327, 79.

30 L. Shechter, J. Wynstra and R. P. Kurkjy, Ind. Eng. Chem., 1956, 48, 94.

31 D. Peerapan, PhD thesis, Lehigh University, 2011.

32 Interfacial rheology, ed. R. Miller and L. Liggieri, CRC Press, 2009.

33 P.-S. Tsai, Y.-M. Yang and Y.-L. Lee, Nanotechnology, 2007, 18, 465604.

34 J. T. Davies and E. K. Rideal, Interfacial Phenomena, Academic Press, New York, 1963.

35 J. Paczesny, K. Sozański, I. Dzięcielewski, A. Zywocinski and R. Hołyst, J. Nanopart. Res., 2012, 14, 826.

36 B. Zhang, Y. Chen, J. Wang, W. J. Blau, X. Zhuang and N. He, Carbon, 2010, 48, 1738.

37 E. Santini, E. Guzmán, F. Ravera, M. Ferrari and L. Liggieri, Phys. Chem. Chem. Phys., 2012, 14, 607.

38 E. Guzman, L. Liggieri, E. Santini, M. Ferrari and F. Ravera, Soft Matter, 2012, 8, 3938. 